Proceedings of SALT 29: 727-747, 2019

\title{
Evidence and Bias: The Case of the Evidential Future in Italian*
}

\author{
Ilaria Frana \\ University of Enna Kore \\ Paula Menéndez-Benito \\ University of Tübingen
}

\begin{abstract}
Evidential markers encode the source of information that an individual (the evidential Origo) has for a proposition. In root declaratives, the Origo is always the speaker (see Korotkova 2016 and references therein). Instead, questions often display interrogative flip: the Origo shifts to the hearer (Garrett 2001; Speas \& Tenny 2003, a.o.). While interrogative flip is widely attested across languages, some evidentials have been reported not to flip in questions (see, e.g., San Roque, Floyd \& Norcliffe 2017; Bhadra 2017). What determines whether evidentials flip or not? Recent work (Korotkova 2016; Bhadra 2017) has proposed that there is a correlation between lack of flip and bias in questions. This paper contributes to our understanding of the interaction of evidentials and bias by investigating the behaviour of questions with the Italian non-predictive future. We characterize the non-predictive future as an inferential evidential marker (see also Mari 2009; Eckardt $\&$ Beltrama forthcoming), and show that lack of flip for the future correlates only with a particular type of bias: a reversal of the default bias associated with negative polar questions (Frana \& Rawlins forthcoming). We trace back this pattern to an interaction between the evidential component of the future and the operator that triggers bias reversal.
\end{abstract}

Keywords: evidentiality, epistemic biases, questions, future, modality

\section{Introduction}

As is well known, evidential markers encode the source of information that an individual (the evidential Origo) has for a proposition (the scope proposition). The Cuzco Quechua examples in (1) illustrate the phenomenon: all of them signal that the speaker has evidence for the claim that it is raining. This evidence is perceptual in (1a), reportative in (1b), and inferential in (1c).

* We are very grateful to the audiences of IGG 45 (University of Padua, February 2019), SALT 29 (UCLA, May 2019), and Expressing Evidence (University of Konstanz, June 2019), as well as to the participants of the Oberseminar New Research in Semantics at the University of Tübingen (summer semester 2019) for their insightful comments and suggestions. Of course, all errors are our own. Our names are listed in alphabetical order.

(C)2019 Frana, Menéndez-Benito 
Frana, Menéndez-Benito

(1)

$$
\begin{aligned}
& \text { a. } \text { Para-sha-n=mi } \\
& \text { rain-PROG-3=DIR } \\
& \text { 'It is raining, I see' } \\
& \text { b. Para-sha-n=si } \\
& \text { rain-PROG-3=REP } \\
& \text { 'It is raining, I hear' } \\
& \text { c. Para-sha-n=chá } \\
& \text { rain-PROG-3=CONJ } \\
& \text { 'It is raining, I gather' }
\end{aligned}
$$

(adapted from Faller 2002: 3)

In root declaratives, the Origo is always the speaker (see, e.g., Korotkova 2016). Instead, in questions, the Origo often shifts to the hearer, a phenomenon that has been dubbed interrogative flip (Garrett 2001; Speas \& Tenny 2003, a.o.). Questions that display interrogative flip signal the source of evidence for the expected answer. Consider the Cheyenne examples in (2). The assertion in (2a) conveys that the speaker has reportative evidence for the scope proposition. The question in (2b) requests the hearer to provide an answer on the basis of reportative evidence.

a. É-némene-sèste Sandy. 3-sing-RPT.3SG Sandy

'Sandy sang, I hear.'

(Murray 2010: 46)

b. Mo=é-némene-sèste Floyd?

$\mathrm{y} / \mathrm{n}=3$-sing-RPT.3SG Floyd

'Given what you heard, did Floyd sing?'

(Murray 2010: 72)

While interrogative flip is a very widely attested interpretation for evidential questions (see Bhadra 2017 for references) some evidentials have been reported not to flip in questions (e.g., San Roque et al. 2017; Bhadra 2017). The Bangla question in (3), where the reportative naki is anchored to the speaker, is a case in point.

(3) Mina naki amerika chol-e ja-cche?

Mina NAKI America go-IMPV go-3P.PRES.PROG

'(Given what I hear), Mina is going away to America (is it true)?'

(Bhadra 2017: 5)

What determines whether evidentials shift in questions or not? Bhadra (2017) and Korotkova (2016) make a link between lack of flip in evidential interrogatives and bias. Korotkova contends that while neutral questions must obligatorily flip, biased questions allow for lack of flip. ${ }^{1}$ Bhadra puts forward a stronger hypothesis:

1 Korotkova (2016) extends this claim to quiz questions, which we will not discuss here. 
that bias in questions and interrogative flip are in complementary distribution. This paper contributes to our understanding of (lack of) flip for evidentials by investigating the behaviour of questions with the Italian non-predictive future, which we analyze as an evidential marker. We will see that, in Italian, lack of flip correlates only with a particular type of bias - a reversal of the default bias normally associated with negative polar questions (as in Frana \& Rawlins forthcoming).

The discussion will proceed as follows: section 2 argues that the Italian nonpredictive future is an evidential. Section 3 shows that while positive polar questions (PPQs) and $w h$-questions with the evidential future exhibit interrogative flip, there is a subset of negative polar questions (NPQs) that do not flip. Section 4 discusses the role that bias plays in this pattern: we show that the questions that do not flip exhibit bias reversal, and suggest that this correlation arises through an interaction between the evidential component of the future and the operator that reverses the default bias for NPQs. Section 5 briefly concludes.

\section{Setting the stage: the basic profile of the evidential future}

Future morphology in Italian can convey not only predictions about the future (as in (4)), but also hypotheses about the present or the past (see, e.g., Bertinetto 1979; Mari 2009; Giannakidou \& Mari 2013, 2018): the speaker of (5) conjectures that Rosa is (/was) at the beach at the time of utterance (/yesterday).

Rosa sarà al mare domani.

Rosa be.FUT.3sg at-the sea tomorrow

'Rosa will be at the beach tomorrow.'

\section{Rosa sarà (/sarà andata) al mare oggi (/ieri).}

Rosa be.FUT.3sg (/be.FUT.3sg gone) at-the sea today (/yesterday)

'Rosa is (/was) at the beach today (/yesterday), I suppose.'

Below, we argue that, on the use illustrated by (5), the future is an inferential evidential marker ${ }^{2}$ (see also Eckardt \& Beltrama forthcoming; Mari 2010). ${ }^{3}$

2 The use of temporal morphology to convey evidentiality is common cross-linguistically (see, e.g., the evidential perfect in Bulgarian, Georgian or Turkish (Izvorski 1997; Smirnova 2012; Koev 2017)).

3 Giannakidou \& Mari (2018) and Farkas \& Ippolito (2019) have recently put forward alternative analyses of the Italian future. Giannakidou \& Mari treat the future as a universal modal akin to must (see also Giannakidou \& Mari 2013). Farkas \& Ippolito convincingly argue that this type of account is not tenable, as the non-predictive future patterns differently from universal modals (see also section 2.1 below). On Farkas \& Ippolito's account, the (non-predictive) future is a non-epistemic modal with a subjective likelihood component. As Farkas \& Ippolito's work was developed in parallel to ours, time constraints prevent us from engaging with their proposal in this paper. 
Frana, Menéndez-Benito

\subsection{The future as an evidential marker}

On its non-predictive use, the Italian future can be characterized as an inferential evidential marker (we will henceforth refer to this use as 'evidential future', abbreviated as 'EF'.) First of all (2.1.1), the EF specifies the source of information for the claim made: it signals that the scope proposition has been inferred from indirect evidence (or it is a mere conjecture based on no evidence at all). Second, the EF has two traits that are shared by evidentials across languages: obligatory speaker-orientation in root assertions (2.1.2) and impossibility of challenging the evidential claim (2.1.3). ${ }^{4}$

\subsubsection{The EF as an inferential evidential}

The EF patterns with inferential evidentials - it is infelicitous when the Origo (the speaker in root assertions, see 2.1.2) has direct evidence for the scope proposition (witness (6)), but felicitous when she has inferred the scope proposition from indirect evidence, as in (7) and (8) (all the examples are adapted from Matthewson 2015). ${ }^{5}$

(6) Context: Speaker smells something good.

\# Qualcosa profumerà.

Something perfume.FUT.3sg

'Something smells good, I suppose.'

(7) Context: Speaker smells a smell like burning meat.

Si sarà bruciata la carne.

CL be.FUT.3sg burnt the meat

'The meat has burnt, I suppose.'

(8) Context: Speaker cooked some chicken in the morning and left it on the kitchen counter. When she gets back in the evening all the chicken is gone. She knows that the dog was alone in the apartment.

Il cane avrà rubato il pollo.

The dog have.FUT.3sg stolen the chicken

'The dog stole the chicken, I suppose.'

4 We will not discuss the predictive use of the future but we would like to note in passing that the predictive use patterns differently from the evidential one with respect to the properties that we discuss here (cf. Giannakidou \& Mari 2013, 2018 for a unified analysis of both uses.)

5 The fact that the EF is infelicitous in direct evidence contexts was also noted by Mari 2010 and Giannakidou \& Mari 2013. These works analyse the EF as an epistemic modal with an evidential requirement, akin to English must (von Fintel \& Gillies 2010), a view that we will not endorse here. 
The inferences conveyed by assertions with the EF vary in their strength: they range from grounded inferences (which can be reinforced by adverbials as in (9), see Bertinetto 1979) to mere guesses (as in (10)). A similar pattern has been reported for other inferential evidentials (see, e.g., Murray 2017 on Cheyenne, and Rullmann, Matthewson \& Davis 2008 on Lilloet Salish. ${ }^{6}$ )

(9) Context: You know that at this time of the day Rosa can only be either at home or at work. You call her home and she is not there. You say:

Allora sarà $\quad\{$ di sicuro, senza dubbio $\}$ a lavoro.

Then be.FUT.3sg \{for sure, without doubt\} at work

'Then she must be $\{$ surely, undoubtedly\} at work.'

(10) Context: it's a sunny day ...

A: Where is Rosa?

B: Non so. Sarà in spiaggia ...

Not know.PRES.1sg. be.FUT.3sg in beach

'I don't know. She might be at the beach ....'

The limiting cases are contexts where the EF presents a conjecture for which the speaker lacks evidence. (11), adapted from Bhadra 2016, illustrates this use (which Bhadra (2016) notes is cross-linguistically common for inferential evidentials). ${ }^{7}$

Evidence-neutral context (The Soldier): Elena's husband is a soldier away at war. His whereabouts are completely unknown at the moment. Carmela is trying to comfort Elena:

Non ti preoccupare, sarà sano e salvo.

Not you worry, be.FUT.3sg sane and safe

'Do not worry, I am sure he is safe and sound.'

6 But note that the translations with must and might used in (9) and (10) are only approximate. Despite the availability of a seemingly might-like interpretation (as in (10)), the EF doesn't allow for conjunctions of incompatible propositions: the example in (i), for instance, is ruled out.

$$
\begin{aligned}
& \text { \# Starà piovendo, ma non starà piovendo. } \\
& \text { be.FUT.3sg raining, but not be.FUT.3sg raining } \\
& \text { 'I assume it is raining, but I assume it is not raining.' }
\end{aligned}
$$

In this, the EF contrasts with the Lilloet Salish inferential evidential k'a (Rullmann et al. 2008). 7 Notice the contrast with epistemic modals like must and might. In (11), a must statement would be blatantly false (and thus inappropriate); a might statement would presumably be true, but pragmatically very different from (11) in that it would lack comforting effect. 
Given the data in this section, we can informally state the evidential contribution of the EF as in (12). ${ }^{8}$

Origo has at most indirect evidence for the scope proposition.

\subsubsection{Speaker-orientation}

One of the hallmarks of evidentials across languages is that they are anchored to the speaker in (root) declaratives (see Korotkova 2016, a.o.). The EF follows this pattern. This can be illustrated by using the scenario in (13), originally designed to show that epistemic modals allow for non-autocentric readings (for discussion, see von Fintel \& Gillies 2011, Yanovich forthcoming, and references therein.) Bill can utter the might statement in (13) but (should he be speaking Italian), he would not be able to utter (14), with the EF. ${ }^{9}$

(13) Context: Ann is planning a surprise party for Bill, but Chris told Bill all about it. Now Bill and Chris are watching Ann set up the party without being discovered. Currently Ann is walking past Chris's apartment carrying a large supply of party hats. She sees a bus on which Bill frequently rides home, so she jumps into some nearby bushes to avoid being spotted. Bill and Chris are both watching from Chris's window and Chris asks Bill why Ann is hiding in the bushes. Bill says:

I might be on that bus.

(Egan, Hawthorne \& Weatherson 2005: 16)

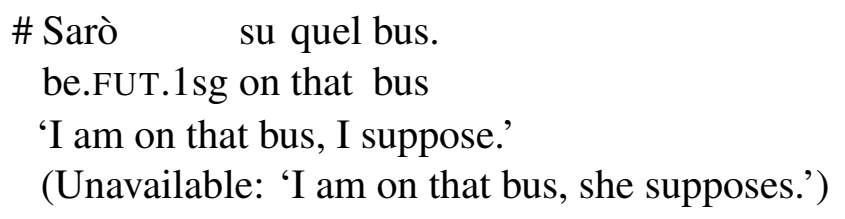

8 This formulation assumes a hierarchy of types of evidence where indirect evidence < direct evidence. On this view, the ban on direct evidence might be derived as a pragmatic inference (see Faller 2012 for a proposal along these lines.)

9 The EF can however combine with according to-phrases that specify that the relevant evidence is that of a third person (see Mari 2010):

(ii) Secondo Pepa, Gianni sarà a casa.

According-to Pepa, Gianni be.fut.3sg at home

'According to Pepa, Gianni is presumably at home.'

We hypothesize that (ii) might be amenable to the same analysis as examples where the EF is embedded under attitudes. In those cases, the EF is always anchored to the attitude holder (one of the possible patterns displayed by evidentials (see Korotkova 2016 and references therein.)) 
Evidence and Bias: The EF in Italian

\subsubsection{Non-challengeability of evidential requirement}

Another cross-linguistically stable property of evidentials is that, while the scope proposition is directly challengeable, the evidential claim is not (see, e.g., Murray 2017 and references therein). The EF patterns once again with evidentials: in (15), that's not true can be used to challenge the scope proposition $p$ (that Luca is ill), but not the evidential claim (that the speaker has at most inferential evidence for $p$ ). An attempt to use that's not true to contest the evidential claim (by stating that B has direct evidence for $p$ ) results in infelicity.
A: Why is Luca absent today?
B: Sarà malato.
FUT.3sg ill
'He is ill, I suppose.'.
C: That's not true. He is perfectly well.
D: \# That's not true. You saw that he was ill.

\subsection{What is at issue? Our take on the EF}

While analyses of evidentials differ with respect to the status of the scope proposition, ${ }^{10}$ many of them share the view that the evidential claim is not-at-issue content (Izvorski 1997; Faller 2002; Murray 2010, 2017, among many others). One of the core arguments for this view is the fact that the evidential claim cannot be directly challenged (2.1.3), a standard test for not-at-issueness (see Diagnostic 1 in Tonhauser 2012). However, Korotkova (2016) questions this argument, and contends that the non-challengeability of the evidential claim is a by-product of subjectivity: as we have seen (section 2.1.2), evidentials (in root assertions) are always interpreted with respect to the speaker's evidence. Korotkova argues that this evidence is privileged information, not accessible to other speakers, and therefore not challengeable. ${ }^{11}$

While we cannot fully engage in the at-issue / not-at-issue debate, we will take the evidential claim of the EF to be not-at-issue, and advance a further argument for not-at-issueness. This argument hinges on the answerhood conditions for questions with the EF. In (16), B's negative answer to A's question cannot target the evidential

10 Some choice points are: is the scope proposition a modalized proposition or not?; is the scope proposition asserted or put forward as some weaker speech act ('presentation', see Faller 2002)? We will not be able to make justice to these debates here.

11 This argument goes back to Papafragou (2006). (Non)-challengeability (which Papagragou calls the assent/dissent test) has been used to argue that subjective modals (Lyons 1977) are not truthconditional. According to Papafragou, subjective modals cannot be challenged /agreed with simply because the type of modality they express "is externally inscrutable" (Papafragou 2006: 1698). 
component: ${ }^{12}$ B rejects the proposition that Gianni went to the gym, not that she has (at most) indirect evidence for whether Gianni went to the gym. This argument does not run into the same issues as the non-challengeability test: A's question displays flip: it requests B to give an answer based on B's own evidence (see section 3). Since B should be able to access her own evidence, the impossibility of targeting the evidential component with a negative answer cannot be due to subjectivity.

$$
\begin{aligned}
& \text { A: Gianni sarà andato in palestra? } \\
& \text { Gianni be.FUT.3sg gone in gym }
\end{aligned}
$$

'Did Gianni go to the gym, what's your guess?'

B: No (he didn't go) / No (\# I saw that he went to the gym).

What kind of not-at-issue content does the evidential requirement of the EF contribute? Presuppositional analyses have been challenged on the grounds that the evidential requirement does not impose a pre-condition on the input context (see, e.g., Tonhauser 2013; Koev 2017). However, Murray (2017) notes that while the evidential requirement in Cheyenne is not presuppositional in assertions, it is in questions. The EF displays the same pattern. B's assertion in (15) is felicitous even if A (wrongly) assumes that B has direct evidence for the answer, but the question in (17) requires a context where it is taken for granted that the addressee has at most indirect evidence for the answer (see section 3 for further discussion).

$$
\begin{aligned}
& \text { Luca sarà malato? } \\
& \text { Luca be.FUT.3sg sick } \\
& \text { 'Is Luca sick, what's your guess?' }
\end{aligned}
$$

Given this, we will take the evidential requirement in questions to be a presupposition (as in Murray 2017) conveying that Origo has at most indirect evidence for the answer. In assertions, the evidential requirement might be another type of not-at-issue content (as Murray claims for Cheyenne), or perhaps a presupposition that is easier to accommodate. As the focus of our paper is on questions, we will not attempt to decide between these two possibilities.

What about the scope proposition? Question-answer pairs strongly suggest that the propositional alternatives in the denotation of questions with the EF are not modal. In (16), B's no answer (necessarily) denies that Gianni went to the gym. Instead, a yes answer would commit B to the claim that Gianni did go to the gym. This contrasts with modal questions like (18), where a yes/no answer could be used

12 This argument has been used to argue that the common ground management operators VERUM and FALSUM are not-at-issue (see Gutzmann \& Miró 2011; Romero 2015; Frana \& Rawlins forthcoming). 
Evidence and Bias: The EF in Italian

to agree/disagree either with the prejacent of the modal or with the modal claim. ${ }^{13}$

(18) A: Might Gianni be at the gym?

B: Yes (he is/he might be).

\section{The evidential future in questions}

This section presents some initial data regarding questions with the EF. We will see that the behaviour of the EF in questions is not uniform. While positive polar questions (PPQs) and wh- questions always display interrogative flip, which aligns with a conjectural interpretation (section 3.1), some negative polar questions (NPQs) allow for lack of flip (section 3.2).

\subsection{Positive polar questions and $w h$-questions}

PPQs and wh- questions with the EF are ruled out when the hearer is assumed to have direct evidence for the answer: the examples in (19) are distinctly odd.
a. \# Sarai sposato?
Be.FUT.2sg married
'Are you married, what's your guess?'
b. \# Quanti anni avrai?
How-many years have.FUT.2sg
'How old are you, what's your guess?'

This follows if the evidential requirement in questions is a presupposition (see section 2.2) and if the questions in (19) display interrogative flip. If so, the Origo parameter will shift to the hearer, and thus the questions in (19) will trigger the presupposition in (20). As any context compatible with world knowledge will fail to satisfy this condition, the questions in (19) are infelicitous.

(20) The hearer has (at most) indirect evidence for the answer.

In contrast, the questions in (21) (that ask the addressee to draw an inference about Gianni's whereabouts) are felicitous, as are the questions in the evidenceneutral scenario in (22) (where the addressee can at best provide a guess.) So far, then, questions with the EF are the mirror image of the assertions in section 2.1.1.

13 If the scope proposition is not modal, a speaker that utters a declarative sentence with the EF cannot be asserting that proposition. An utterance of $F U T(p)$ often conveys a weakened commitment towards $p$. This is compatible with a Faller-style analyis (e.g., Faller 2002) on which declaratives with the EF would put forward the scope proposition by means of a speech act weaker than assertion (see also Zimmermann 2008 for a proposal along these lines for German wohl.) 
(21) Context: S knows that H doesn't know where Gianni is at the moment, but she also knows that $\mathrm{H}$ is familiar with Gianni's habits. S asks:
a. Gianni sarà
a casa a quest'ora?

Gianni be.FUT.3sg. at home at this-hour

'Is Gianni at home at this time of the day, what's your guess?'

b. Dove sarà Gianni a quest'ora?

Where be.FUT.3sg. Gianni at this-hour

'Where is Gianni at this time of the day, what's your guess?'

(22) Evidence-neutral context (The Soldier): S's husband is a soldier away at war. His whereabouts are completely unknown. Seeking comfort, S asks H:

a. Sarà sano e salvo?

be.FUT.3sg sound and safe

'Is he safe and sound, what's your guess?'

b. Dove sarà?

where be.FUT.3sg

'Where is he, what's your guess?'/ 'Where could he be?'

Some remarks about the evidence-neutral scenario (22) are in order. As noted above, the best the hearer can do in this type of context is to advance a conjecture. We further note that not answering would be an unmarked conversational move in this case. Thus, this example aligns with what the literature dubs conjectural questions (attested for inferential evidentials in a number of languages), which do not require the hearer to answer (Littell, Matthewson \& Peterson 2010; Murray 2017 , a.o.). The standard assumption in the literature is that conjectural questions have a source different from interrogative flip (see discussion in Eckardt Submitted). However, we contend that in the case of the EF, questions like the ones in (22) do instantiate flip: they are the flipped version of assertions in evidence-neutral contexts. In what follows, we will use 'conjectural questions' as a cover term to refer to questions for which the hearer is not expected to know the answer, including both questions where the hearer is asked to provide an evidence-based inference and questions where the hearer can only advance an (ungrounded) guess.

\subsection{Negative polar questions}

While PPQs and $w h$-questions consistently display interrogative flip, NPQs exhibit a mixed pattern. Consider first the context in (23). In this context, the speaker cannot ask Ana the question in (23a) but he could in principle ask the question in (23b) to Bea (while pointing at Ana discreetly). This is all as expected: the presupposition of 
(23a) is not met in this context (Ana has direct evidence regarding the question of whether she is hungry), but the presupposition of (23b) is met (Bea is not expected to have direct evidence regarding that question). Just like the questions in 3.1, the NPQs in (23) have a conjectural interpretation (which we argue correlates with flip).

(23) Context (no appetite): S invited Ana and Bea for dinner and made it clear that he was going to cook up a storm. At dinner, Ana barely touches her food.
a. \# Non avrai fame? (addressing Ana)
not have.FUT.2sg hunger?
'Are you not hungry, what's your guess?'
b. Non avrà fame? (addressing Bea)
not have.FUT.3sg hunger?
'Is she not hungry, what's your guess?'

But now consider the context in (24). Here, the speaker can pose the question in (24) to the hearer. This is unexpected: the presupposition that, given what we have said, should be triggered by the EF in (24) is not met in this context.

(24) Context (insatiable): $\mathrm{S}$ and $\mathrm{H}$ had a big lunch and are now sitting at a bar for drinks. $\mathrm{H}$ asks for the food menu. $\mathrm{S}$ asks $\mathrm{H}$ :
Non avrai
mica fame?
not have.FUT.2sg. NEG-PART hunger?

'Am I right in guessing that you are not hungry?' (very roughly)

Why is a non-conjectural interpretation possible here? In what follows, we will argue that the availability of the non-conjectural interpretation for NPQs like the one in (24) is crucially tied to the type of bias displayed by these questions. The negative particle mica will be an important player in this story.

\section{The role of bias}

In this section, we examine the role that bias plays in the surprising pattern presented in section 3.2. In section 4.1, we introduce some crucial background on biased questions in Italian: Italian NPQs (just like NPQs in many other languages) trigger a default positive bias. The negative marker mica reverses this default bias (Frana $\&$ Rawlins 2016, forthcoming). In section 4.2, we show that the non-conjectural interpretation for NPQs with the EF is only available in bias reversal cases. Finally, in section 4.3, we suggest that this correlation arises via an interaction of the evidential component of the EF and mica. 
Frana, Menéndez-Benito

\subsection{Background: Italian NPQs and mica}

Cross-linguistically, NPQs signal that the speaker had a pre-existing bias for the positive answer (Ladd 1981; Büring \& Gunlogson 2000; Romero \& Han 2004, a.o.). The example in (25) illustrates this for Italian: B's question conveys that she assumed that A had talked to Rosa recently, an assumption contradicted by A's assertion. In contradiction scenarios like this one the speaker may use an NPQ with the intention of double-checking whether her prior expectation is still the case.

A: I haven't talked to Rosa in a long time.

B: Non ti aveva telefonato qualche giorno fa?

NEG you-CL have.PAST.3sg called few day ago

'Didn't she call you a few days ago?'

Frana \& Rawlins (2016, forthcoming) show that Italian mica reverses the polarity of this default bias (from positive to negative). The remainder of this section briefly presents some basic background on mica and illustrates its bias reversal effect.

Mica is a negative marker that appears in declaratives and polar questions (Cinque 1976; Zanuttini 1997; Frana \& Rawlins 2016, a.o.). In declaratives, mica is limited to denials: it is inappropriate, e.g., in (26), where B is putting forward a new negative proposition, but appropriate in (27), where B is challenging A's assertion. ${ }^{14} 15$

A: Who is married?

B: Io non sono (\#mica) sposato.

I not be.PRES.1sg (\#MICA) married

'I am not married.'

A: You are married.

B: No, non sono (mica) sposato.

No. Not be.PRES.1sg (MICA) married

'No. I am NOT married.'

While in assertions mica is felicitous in a subset of the cases that allow for plain negation (non), in polar questions mica and plain negation are in complementary distribution. More specifically, mica reverses the default bias of NPQs: NPQs with

14 Mica can also deny previously introduced presuppositions and implicatures. See Frana \& Rawlins forthcoming for illustration of the full range of denial contexts that license mica in assertions.

15 Mica may occur in combination with non, as in (26) and (27), but also as an autonomous negative element (e.g. Mica sono sposato). Following Frana \& Rawlins, we assume that the autonomous and the discontinuous forms are, at least in some dialects, semantically and pragmatically equivalent; all the examples in this paper employ the discontinuous form. 
mica signal negative bias. This can be illustrated with the examples in (28) and (29), from Frana \& Rawlins forthcoming. (28) sets up a context in which the speaker had a prior expectation for the positive answer, but now encounters evidence for the opposite. In this scenario, the plain NPQ in (28a) is felicitous but the NPQ with mica in (28b) is not. In contrast, in (29), the speaker had a prior bias for the negative answer and is now faced with counter-evidence. Now, the reverse judgments obtain: the NPQ in (29a) is infelicitous while the NPQ with mica in (29b) is felicitous. ${ }^{16}$

(28) Positive bias (S expected $p$, evidence against $p$ ). Clara invites Miles for drinks late in the evening and tells him to come after dinner. When he gets there, Miles asks if she has any food. Clara asks him:

a. Non hai già mangiato?

not have.PRES.2sg already eaten?

'Didn't you eat already?'

b. \# Non hai mica già mangiato? not have.PRES.2sg MICA already eaten?

(29) Negative bias (S expected $\neg p$, evidence for $p$ ). Clara invites Miles for dinner and makes clear to him that she will prepare her best dishes. When he gets there, Miles barely touches any food. Clara asks him:
a. \# Non hai già mangiato?
not have.PRES.2sg already eaten?
'Didn't you eat already?'
b. Non hai mica già mangiato?
not have.PRES.2sg MICA already eaten?

\subsection{Bias and the (non)-conjectural interpretation: the pattern}

In this section we show that the non-conjectural interpretation of the EF in NPQs is only available in bias reversal cases. Consider first our no appetite context, repeated (in a simplified version) in (30). In this scenario, the speaker has a pre-existing bias for the positive answer (and therefore the NPQ in (30a) is felicitous). Here, the NPQ with the EF in (30b) can only have a conjectural interpretation, which gives rise to oddity (as this is a question whose answer the hearer is expected to know).

16 Frana \& Rawlins do not provide translations for mica NPQs since English has no exact equivalent of mica. For this example, they suggest the following approximate paraphrases: 'oh no, you didn't eat, did you' and 'you were not supposed to eat...did you?' (Frana \& Rawlins forthcoming: fn.16). 
(30) Positive bias (no appetite): $\mathrm{S}$ invited $\mathrm{H}$ for dinner and made it clear that he was going to cook up a storm. $\mathrm{H}$ barely touches her food. $\mathrm{S}$ asks $\mathrm{H}$ :
a. Non hai fame?
not have.PRES.2sg hunger?
'Aren't you hungry?'
b. \# Non avrai fame?
not have.FUT.2sg hunger?
'Are you not hungry, what's your guess?'

Now, let's go back to our insatiable context, repeated in (31). In this scenario, the speaker is biased towards the negative answer (so the NPQ in (31a) is infelicitous). Here, the question with the EF (and mica) can have a non-conjectural interpretation, witness the acceptability of $(31 \mathrm{~b}) .{ }^{17}$

(31) Negative bias (insatiable): $\mathrm{S}$ and $\mathrm{H}$ had a big lunch and are sitting at a bar for drinks. $\mathrm{H}$ asks for the food menu. $\mathrm{S}$ asks $\mathrm{H}$ :
a. \# Non hai fame?
not have.PRES.2sg hunger?'
'Aren't you hungry?'
b. Non avrai mica fame?
not have.FUT.2sg MICA hunger?
'Am I right in guessing that you are not hungry?' (very roughly)

\subsection{Bias and the (non)-conjectural interpretation: towards an explanation}

We have shown that the non-conjectural interpretation of the EF is only available in NPQs when the default bias is reversed. Where does this correlation come from? In this section, we will sketch an approach along the following lines: Frana \& Rawlins (2016, forthcoming) analyze mica as a common ground management operator that is always anchored to the speaker (section 4.3.1 gives some minimal background on common ground management and provides a summary of Frana \& Rawlins's account). We propose (section 4.3.2) that the presence of mica forces the EF to be speaker-oriented (i.e., blocks interrogative flip). In turn, lack of flip yields a non-conjectural interpretation.

17 At least for some speakers, it is possible to omit mica in (31b). However, bias reversal in (31b) (and therefore the non-conjectural interpretation of this question) only obtains with the intonational contour normally associated with mica NPQs. A characterization of the intonational patterns associated with different types of biased questions is beyond the scope of this paper. 
Evidence and Bias: The EF in Italian

\subsubsection{Biases and CG-management}

As we have seen, NPQs like (32a) signal positive bias on the part of the speaker. In contrast, polar questions with focus stress or epistemic really convey negative bias: the questions in (32b) indicate that the speaker expected Pepa not to go.

(32) a. Isn't Pepa going?

b. Is Pepa GOING? / Is Pepa really going?

According to a prominent line of research (Romero \& Han 2004; Repp 2013; Frana \& Rawlins forthcoming, a.o.), biases in polar questions can be derived by assuming that really (or verum focus) and (high) negation contribute the commonground (CG) management operators VERUM and FALSUM, respectively. These operators can also occur in assertions, as in (33) (FALSUM in assertions corresponds to the focused negation used in denials).

a. Pepa really is going.

b. Pepa is NOT going.

VERUM and FALSUM are perspectival meta-conversational operators that combine with a proposition $p$ and convey that a discourse agent (the speaker or the hearer) is sure about $p$ being (VERUM) or not being (FALSUM) in the common ground. We will assume the denotations in (34) and (35), where the common ground management component is modelled as a presupposition on the input context. On this view, the denotation of FALSUM $p$, e.g., is only defined in a world $w$ and context $c$ if the Origo of $c$ is sure in $w$ that in all the worlds satisfying their conversational goals $p$ is not common ground. When defined, FALSUM $p$ is true in $w$ iff $p$ is false in $w$ (i.e., at the truth-conditional level FALSUM contributes negation).

$$
\begin{aligned}
& \llbracket \text { VERUM } \rrbracket^{c, w}=\lambda p \cdot p \\
& \text { Defined for } p, c, w \text { iff } \\
& \forall w^{\prime} \in \text { Epist }_{\text {Origo }_{c}}(w):\left(\forall w^{\prime \prime} \in \text { Conv }_{\text {Origo }_{c}}\left(w^{\prime}\right): p \in C G_{w^{\prime \prime}}\right)
\end{aligned}
$$

(Frana \& Rawlins forthcoming, based on Romero \& Han 2004)

$$
\begin{aligned}
& \llbracket \text { FALSUM } \rrbracket^{c, w}=\lambda p . \neg p \\
& \quad \text { Defined for } p, c, w \text { iff } \\
& \forall w^{\prime} \in \text { Epist }_{\text {Origo }_{c}}(w):\left(\forall w^{\prime \prime} \in \text { Conv }_{\text {Origo }_{c}}\left(w^{\prime}\right): p \notin C G_{w^{\prime \prime}}\right)
\end{aligned}
$$

(Frana \& Rawlins forthcoming, based on Repp 2013)

Frana \& Rawlins note that these operators are akin to evidentials in that they display interrogative flip: their perspectival centre (Origo) is the speaker in (root) assertions and the addressee in questions. Following some of the literature on 
evidentials (see e.g., Bhadra 2017 and references therein), they assume that the Origo is effectively bound by the speech-act operator in Force-P, as illustrated in the (simplified) LFs in (36).

a. $\left[\operatorname{ASSERT}_{S}\left[\right.\right.$ FALSUM $_{S}[$ Pepa is going]]]

b. $\left[\mathrm{Q}_{\mathrm{H}}\left[\right.\right.$ FALSUM $_{\mathrm{H}}[$ Pepa is going $\left.\left.]\right]\right]$

To see how this plays out in NPQs, consider the dialogue in (37). Given interrogative flip, the Origo parameter is set to the hearer. Accordingly, the presupposition of S's question is hearer-oriented, as shown in (38). The question is only defined if the hearer $(\mathrm{H})$ is sure that in all the worlds satisfying her conversational goals it is not common ground that she is going out. In (37), the presupposition is satisfied: $\mathrm{H}$ asserted that she is staying home, which entails that she is not going out. Given this, the question is defined (and thus denotes the set of its possible answers, see (38)).

H: I am staying home.

S: Aren't you going out?

$$
\begin{aligned}
& \left.\llbracket\left[\mathbf{Q}_{\mathrm{H}}\left[\mathbf{F A L S U} \mathbf{M}_{\mathrm{H}}[\mathbf{H} \text { is going out }]\right]\right]\right]^{c, w}=\{p, \neg p\} \\
& \text { Defined for } p, c, w \text { iff } \\
& \forall w^{\prime} \in \operatorname{Epist}_{H_{c}}(w):\left(\forall w^{\prime \prime} \in \operatorname{Conv}_{H_{c}}\left(w^{\prime}\right): p \notin C G_{w^{\prime \prime}}\right)
\end{aligned}
$$

The positive bias associated with S's question arises through a pragmatic competition. Following Romero \& Han 2004, Frana \& Rawlins take CG-management operators to be meta conversational moves whose choice over a simpler competitor (a plain question) should be motivated. This is stated in the principle in (39).

(39) Principle of Economy Do not use a meta-conversational move unless necessary (to resolve a Quality dilemma).

(Frana \& Rawlins forthcoming, after Romero \& Han 2004)

One type of situation where a quality dilemma arises is when the speaker is in a state of epistemic conflict ( $\mathrm{S}$ has a pre-existing bias and the context presents counter-evidence). This explains why biased questions are felicitous in contradiction scenarios: if $\mathrm{S}$ believed $p$ but $\mathrm{H}$ produced evidence against $p, \mathrm{~S}$ is justified in questioning the appropriateness of adding $p$ to the CG in order to resolve her epistemic conflict. ${ }^{18}$ In (37), S's choice of a question with FALSUM indicates that she is facing a quality dilemma. Since $\mathrm{H}$ gave evidence for the negative answer, $\mathrm{S}$ must have had a prior bias for the positive answer (i.e., that $\mathrm{H}$ is going out).

Now, let us address mica. On Frana \& Rawlins's analysis, mica introduces a FALSUM operator that is necessarily anchored to the speaker, as shown in (40).

18 Frana \& Rawlins also discuss other possible sources of quality dilemmas. The reader is referred to their work for details. 
Evidence and Bias: The EF in Italian

$$
\llbracket \mathbf{m i c a} \rrbracket^{c}=\llbracket \text { FALSUM } \rrbracket^{c / \text { Origo } \rightarrow s_{c}, w}
$$

On this view, mica in polar questions does not undergo interrogative flip. This perspectival stability leads to bias reversal. Consider again Frana \& Rawlins's dinner scenarios in (28) and (29). The mica question in those scenarios is interpreted as in (41). This question presupposes that the speaker is sure that $p$ (that $\mathrm{H}$ has already eaten) should not be CG (negative bias). The presupposition is satisfied only in (29) where $\mathrm{S}$ believed $\neg p$ was an established expectation. Moreover, given that $\mathrm{S}$ is posing a meta-question, she must be trying to resolve an epistemic conflict. In (29), there is contextual evidence against her prior expectation (Miles' apparent lack of appetite). Thus, $\mathrm{S}$ is facing a quality-dilemma (epistemic conflict) and can therefore ask the meta-question without incurring in a violation of the Principle of Economy.

$$
\begin{aligned}
& \llbracket\left[\mathbf{Q}_{\mathrm{H}}\left[\operatorname{FALSUM}_{\mathrm{S}}[\mathrm{H} \text { ate already }]\right]\right] \rrbracket^{c, w}=\{p, \neg p\} \\
& \text { Defined for } p, c, w \text { iff } \\
& \forall w^{\prime} \in \operatorname{Epist}_{S_{c}}(w):\left(\forall w^{\prime \prime} \in \operatorname{Conv}_{S_{c}}\left(w^{\prime}\right): p \notin C G_{w^{\prime \prime}}\right)
\end{aligned}
$$

\subsubsection{Back to the $\mathrm{EF}$}

We are now ready to address the pattern displayed by the EF in NPQs. Recall our generalization: non-conjectural interpretations are only available for NPQs where the default bias is reversed. This was illustrated with the example in (24), where $\mathrm{H}$ asks for the menu after having a big lunch, and $\mathrm{S}$ asks the question repeated in (42).

Non avrai mica fame?

not have.FUT.2sg. MICA hunger?

'Am I right in guessing that you are not hungry'?' (very roughly)

In section 4.3.1, we saw that mica introduces a speaker-oriented FALSUM operator that blocks interrogative flip. As this operator sets the Origo parameter of the context to the speaker, it forces the EF to also be speaker-oriented. Thus, the LF in (43b) is blocked for a NPQ containing both mica and the EF. The only possible LF for this kind of question is (43a). ${ }^{19}$

$$
\begin{aligned}
& \text { a. }\left[\mathrm{Q}_{\mathbf{H}}\left[\operatorname{FALSUM}_{\mathbf{S}}\left[\mathrm{FUT}_{\mathbf{S}} p\right]\right]\right] \\
& \text { b. }\left[\mathrm{Q}_{\mathbf{H}}\left[\operatorname{FALSUM}_{\mathbf{S}}\left[\mathrm{FUT}_{\mathbf{H}} p\right]\right]\right]
\end{aligned}
$$

19 We have noted in passing that mica is optional in bias reversal questions with the EF (see fn. 17). This suggests that the operator denoted by mica can be covert in such cases. This operator seems to always be covert in Spanish, whose EF patterns like the Italian one with respect to the data discussed in this paper, but where there is no overt particle that indicates bias reversal. 
Given this, (42) triggers two presuppositions. First, due to mica, (42) presupposes that the speaker is sure that $p$ (that $\mathrm{H}$ is hungry) should not be CG. This presupposition is satisfied in the given scenario, where the speaker was biased towards $\neg p$. Second, the EF introduces the presupposition that the speaker has at most indirect evidence for the answer (also satisfied in the scenario). Nothing is presupposed about the evidence available to the hearer, and therefore the question is felicitous even though the hearer can be assumed to have direct evidence for the answer. Note that nothing prevents the EF from flipping in NPQs with positive bias, which involve regular FALSUM. As a result, these NPQs get a conjectural interpretation (as in (30)).

This setup makes a further prediction: since biased PPQs with the EF involve VERUM, which is always hearer-oriented in questions (see 4.3.1), they should only get a conjectural interpretation. This prediction is borne out. We have seen that the question in (19a), where the hearer is expected to know the answer, is ruled out (it presupposes that the hearer has (at most) indirect evidence for the answer). Adding davvero ('really') does not get rid of the oddity, witness (44).

$$
\begin{aligned}
& \text { \# Davvero sarai sposato? } \\
& \text { really be.FUT.2sg married }
\end{aligned}
$$

'Are you really married, what's your guess?'

\section{To conclude}

Recent work (Korotkova 2016; Bhadra 2017) draws a correlation between lack of flip in evidential interrogatives and bias. This paper brings to the arena novel data that show that this correlation is only partial. As we have seen, the EF displays mixed behaviour in NPQs: NPQs with positive (default) bias flip (which results in a conjectural interpretation) but NPQs with negative bias do not flip (and thus allow for a non-conjectural interpretation). We have argued that what triggers lack of flip is the presence of a CG management operator that sets the speaker as the Origo parameter. This work raises the question of whether evidentials across languages show analogous interactions with CG management operators, thereby opening up a line of research that brings together two domains of inquiry that have had limited overlap until now. 
Evidence and Bias: The EF in Italian

\section{References}

Bertinetto, Pier Marco. 1979. Alcune ipotesi sul nostro futuro (con alcune osservazioni su potere e dovere). Rivista di grammatica generativa 4. 77-138.

Bhadra, Diti. 2016. Uttering evidentials without evidence. In ConSOLE XXIV, 1-18.

Bhadra, Diti. 2017. Evidentiality and questions: Bangla at the interfaces: Rutgers University PhD dissertation.

Büring, Daniel \& Christine Gunlogson. 2000. Aren't positive and negative polar questions the same? Manuscript UCSC/UCLA.

Cinque, Guglielmo. 1976. Mica. Annali della Facoltà di Lettere e Filosofia dell'Università di Padova 1. 101-112.

Eckardt, Regine. Submitted. Evidentials and conjectural questions.

Eckardt, Regine \& Andrea Beltrama. forthcoming. Evidentials and questions. In Christopher Piñon (ed.), Empirical issues in syntax and semantics 12, CSSP.

Egan, Andy, John Hawthorne \& Brian Weatherson. 2005. Epistemic modals in context. In Gerhard Preyer \& Georg Peter (eds.), Contextualism in philosophy, 131-170. Oxford University Press.

Faller, Martina. 2002. Semantics and pragmatics of evidentials in Cuzco Quechua: Stanford University $\mathrm{PhD}$ dissertation.

Faller, Martina. 2012. Evidential scalar implicatures. Linguistics and Philosophy 35. 285-312.

Farkas, Donka \& Michela Ippolito. 2019. Epistemic stance without epistemic modals: the case of the presumptive future. In Katherine Blake, Forrest Davis, Kaelyn Lamp \& Joseph Rhyne (eds.), SALT 29, 459-476.

von Fintel, Kai \& Anthony Gillies. 2010. Must ... stay ... strong! Natural Language Semantics 4(18). 351-383.

von Fintel, Kai \& Anthony S. Gillies. 2011. Might made right. In Andy Egan \& Brian Weatherson (eds.), Epistemic modality, 108-130. Oxford University Press. http://mit.edu/fintel/fintel-gillies-2011-mmr.pdf.

Frana, Ilaria \& Kyle Rawlins. 2016. Italian mica in assertions and questions. In Nadine Bade, Polina Berezovskaya \& Anthea Schöller (eds.), SuB 20, 234-251.

Frana, Ilaria \& Kyle Rawlins. forthcoming. Attitudes in discourse: Italian polar questions and the particle mica. Semantics and Pragmatics .

Garrett, Edward John. 2001. Evidentiality and assertion in Tibetan: UCLA PhD dissertation.

Giannakidou, Anastasia \& Alda Mari. 2013. The future of Greek and Italian: An evidential analysis. In E. Chemla, V. Homer \& G. Winterstein (eds.), SuB 17, 255-270.

Giannakidou, Anastasia \& Alda Mari. 2018. A unified analysis of the future as epistemic modality: the view from Greek and Italian. Natural Language and 
Linguistic Theory 36(1). 85-129. doi:10.1007/s11049-017-9366-z.

Gutzmann, Daniel \& Elena Castroviejo Miró. 2011. The dimensions of VERUM. In Olivier Bonami \& Patricia Cabredo Hofherr (eds.), Empirical issues in syntax and semantics 8, 143-165. CSSP.

Izvorski, Romyana. 1997. The present perfect as an epistemic modal. In Brendan Jackson (ed.), SALT 12, 222-239.

Koev, Todor. 2017. Evidentiality, learning events, and spatiotemporal distance: The view from Bulgarian. Journal of Semantics 34(1). 1-41. doi:10.1093/jos/ffv014.

Korotkova, Natalia. 2016. Heterogeneity and uniformity in the evidential domain: UCLA PhD dissertation.

Ladd, D. Robert. 1981. A first look at the semantics and pragmatics of negative questions and tag questions. In CLS 17, 164-171.

Littell, Patrick, Lisa Matthewson \& Tyler Peterson. 2010. On the semantics of conjectural questions. In Tyler Peterson \& Uli Sauerland (eds.), Evidence from evidentials, vol. 28 University of British Columbia Working Papers in Linguistics, 89-104. University of British Columbia.

Lyons, John. 1977. Semantics. Cambridge University Press.

Mari, Alda. 2009. Disambiguating the Italian future. In Generative Lexicon, 209216.

Mari, Alda. 2010. On the evidential nature of the Italian future. HAL archivesouvertes.fr.

Matthewson, Lisa. 2015. Evidential restrictions on epistemic modals. In Luis Alonso-Ovalle \& Paula Menéndez-Benito (eds.), Epistemic indefinites, 141-160. Oxford University Press.

Murray, Sarah. 2010. Evidentiality and the structure of speech acts: Rutgers University $\mathrm{PhD}$ dissertation. doi:10.7282/T3RX9BTJ.

Murray, Sarah. 2017. The semantics of evidentials. Oxford Studies in Semantics and Pragmatics. Oxford University Press.

Papafragou, Anna. 2006. Epistemic modality and truth conditions. Lingua 116. 1688-1702.

Repp, Sophie. 2013. Common ground management: modal particles, illocutionary negation and verum. In Daniel Gutzmann \& Hans-Martin Gärtner (eds.), Beyond expressives - explorations in use-conditional meaning CRISPI Series, 231-274. Leiden, Boston: Emerald.

Romero, Maribel. 2015. High negation in subjunctive conditionals and polar questions. In Eva Csipak \& Hedde Zeijlstra (eds.), SuB 19, 320-337.

Romero, Maribel \& Chung-Hye Han. 2004. On negative Yes/No questions. Linguistics and Philosophy 27(5). 609-658.

Rullmann, Hotze, Lisa Matthewson \& Henry Davis. 2008. Modals as distributive indefinites. Natural Language Semantics 16. 317-315. 
San Roque, Lila, Simeon Floyd \& Elisabeth Norcliffe. 2017. Evidentiality and interrogativity. Lingua 186. 120-143.

Smirnova, Anastasia. 2012. Evidentiality in Bulgarian: temporality, epistemic modality, and information source. Journal of Semantics 30. 479-532.

Speas, Margaret \& Carol Tenny. 2003. Configurational properties of point of view roles. In Anna Maria Di Sciullo (ed.), Asymmetry in grammar, vol. 1 (Linguistik Aktuell/Linguistics Today 57), 315-344. John Benjamins. doi:10.1075/la.57.15spe.

Tonhauser, Judith. 2012. Diagnosing (not-)at-issue content. In Elizabeth BogalAllbritten (ed.), SULA 6, UMass GLSA.

Tonhauser, Judith. 2013. Reportative evidentiality in paraguayan Guaraní. In H. Greene (ed.), SULA 7, 189-204. GLSA.

Yanovich, Igor. forthcoming. Epistemic modality. In H. Rullman L. Matthewson, C. Meier \& T. E. Zimmerman (eds.), Blackwell companion to semantics, Wiley. Zanuttini, Raffaella. 1997. Negation and clausal structure: a comparative study of romance languages. Oxford University Press.

Zimmermann, Malte. 2008. Discourse particles in the left periphery. In C. Maienborn B. Shaer \& W. Frey (eds.), Dislocated elements in discourse: syntactic, semantic, and pragmatic perspectives, 200-231. London: Routledge.

Ilaria Frana

University of Enna Kore

Viale delle Olimpiadi 1, 94100,

Enna, Italy

ilaria.frana@unikore.it
Paula Menéndez-Benito University of Tübingen

Wilhelmstrasse 50, 72074, Tübingen, Germany paula.menendez-benito@es.uni-tuebingen.de 